\title{
Indicadores para um modelo de análise do jogo de handebol na categoria Sub-14 a partir da opinião de treinadores
}

https://doi.org/10.11606/issn.1981-4690.ی35i1p129-141

\author{
Mayara Gonçalves Madeira* \\ Maria Luísa Dias Estriga** \\ Rafael Pombo Menezes*
}

*Escola de Educação

Física e Esporte

de Ribeirão Preto,

Universidade de São

Paulo, Ribeirão Preto,

SP, Brasil.

**Faculdade de

Desporto, Universidade

doPorto, Porto, Portugal.

\section{Resumo}

Diferentes métodos têm sido utilizados para a análise do jogo de handebol pautados em indicadores da categoria adulta, de difícil generalização para outras categorias (como a sub-14). 0 objetivo deste estudo foi mapear os indicadores relevantes para a análise do jogo no domínio da categoria sub-14 do handebol, com base na opinião de treinadores de handebol $(n=6)$. Para este efeito, foram relizadas entrevistas com treinadores do Estado de São Paulo, analisadas a partir do método do Discurso do Sujeito Coletivo. Indicadores para a análise de jogo foram determinados a partir da análise da opinião dos inquiridos e por recurso a fontes documentais (textos técnicos). Foram identificados 18 indicadores relacionados com os fundamentos técnico-táticos individuais (11 defensivos e sete ofensivos) e 12 relacionados aos meios táticos grupais e coletivos (cinco defensivos e sete ofensivos). Os indicadores remetem à necessidade de se considerar os constrangimentos situacionais em que se manifestam. Sugere-se, assim, que as propostas para a análise de jogo nessa categoria considerem as relações entre companheiros e adversário, tendo por base as unidades táticas funcionais $1 \times 1,2 \times 2$ e $3 \times 3$. Espera-se que esta abordagem permita contribuir para um melhor entendimento da dinâmica de jogo, indo além da mera contabilização do número de ocorrências por indicador de análise.

Palavras-chave: Esportes coletivos; Análise de jogo; Handebol; Indicadores de desempenho; Treinadores.

\section{Introdução}

O handebol é um jogo esportivo coletivo de invasão caracterizado pelo confronto entre duas equipes, com interesses antagônicos, que disputam a posse da bola, num espaço comum e com possibilidades de contato físico ${ }^{1}$. Também se caracteriza pela alternância entre as fases (ofensiva e defensiva) determinadas pela posse ou não da bola e com princípios específicos ${ }^{2}$. O cenário técnico-tático do jogo é configurado pelas suas fases, pelos comportamentos dos jogadores e pelos seus conteúdos específicos, dentre os quais se destacam os sistemas de jogo (ofensivos e defensivos), os fundamentos técnicotáticos (ofensivos e defensivos) ${ }^{3,4, a}$ e os meios técnico-táticos coletivos (ofensivos e defensivos) conforme proposto por Greco, Silva e Greco5.

As competências de análise do jogo de handebol e da sua relação com a preparação esportiva de uma equipe são absolutamente nucleares para o desempenho das tarefas de um treinador de handebol. Não obstante o interesse crescente da comunidade científica acerca da temática da análise de jogo, a formalização e a sistematização dos sistemas de análise ainda é incipiente.

A análise do jogo ou da performance esportiva tem sido realizada a partir do estudo de diferentes indicadores que supostamente estão relacionados com jogo e por recurso a dois tipos de abordagens: a) abordagem estática, que registra descritivamente açôes com pouca ou nenhuma referência ao contexto do jogo e, b) abordagem dinâmica, que registra as ações de acordo com o processo correspondente no momento do jogo ${ }^{6}$. 
Análises de diferentes aspectos técnicos e técnicotáticos durante jogos e treinos vêm sendo propostas para buscar compreender o complexo cenário do jogo ${ }^{7,8} \mathrm{e}$ identificar padróes de jogo ou comportamentos mais eficazes ${ }^{9,10}$. Nesse sentido, diferentes autores sugerem que tais análises podem ser utilizadas como fonte de informaçóes pelos treinadores para o treinamento das equipes, para aprimorar diferentes comportamentos individuais, grupais e coletivos ${ }^{8-11}$.

A busca por parâmetros que caracteizem o jogo de handebol envolve abordagens diversas, que vão desde a simples identificação e a quantificação de indicadores de performance de cunho individual ${ }^{12,13}$ até abordagens com recurso a técnicas de análise mais sofisticadas e matematizadas ${ }^{14,15}$. Prudente ${ }^{16}$ aponta que essa metodologia com recurso à análise sequencial (embora estática) tem como vantagens apresentar dados além do número de ocorrências das açôes, considerando a sua ordem durante o jogo.

Embora os recursos tecnológicos tenham se aperfeiçoado nas últimas décadas, permitindo arquivar e analisar quantidades maiores de dados, pouco se avançou na compreensão das situaçóes do jogo de handebol e da sua dinâmica, dado que a maioria das análises focam variáveis isoladas de seu contexto espaço-temporal e não consideram a localização da bola (elemento central do jogo). Decorrente dos vários tipos de estudos disponíveis, fica evidente que a análise de jogo tem sido refém das possibilidades de estudo que as técnicas de análise standard permitem (de que é exemplo a análise sequencial), quando se impóe o inverso. Isto é, primeiro importa perceber o que valoriza o treinador (expert), o que "vê", que significado lhe atribuiu, e só depois passar ao desenvolvimento de técnicas e procedimentos mais apropriados. Para este efeito, é determinante

\section{Método}

Um delineamento qualitativo de pesquisa foi utilizado para extrair informaçáo de natureza descritiva ${ }^{26}$, partindo dos discursos dos treinadores sobre os aspectos de jogo (parâmetros técnicos e táticos) preponderantes para analisar o jogo na categoria sub-14 do handebol. Os métodos qualitativos são frequentemente utilizados para buscar compreender fenômenos sociais, de maneira que seja possível obter informação mais identificar, formalizar as "boas" variáveis e estabelecer critérios que possibilitem extrair a informaçáo relevante, atendendo a parâmetros tempo-espaço, posição da bola e interação entre companheiros e adversários ${ }^{8}$.

Os discursos dos treinadores, fonte de informaçóes deste estudo, descrevem o contexto de atuação profissional no qual desenvolvem suas açôes, exteriorizando concepções sobre o jogo de handebol e, em especial, sobre sua análise. Não está no centro desta discussão se os treinadores fazem (bem) o que é relatado nos discursos, mas que tais argumentos compóem a percepção que possuem da matriz de jogo nessa categoria. Para isso é importante observar a realidade dos treinadores a partir de uma perspectiva sistemática, precisa e, ao mesmo tempo, identificando suas intençôes e suas crenças ${ }^{17}$.

Estudos mais recentes no handebol trazem como objeto de análise aspectos como as variáveis que influenciam no resultado final ${ }^{18}$, variáveis descritivas e estatísticas ${ }^{19}$, indicadores de desempenho ${ }^{20-22}$ e relação entre variáveis de treino e de jogo ${ }^{23}$. Tais estudos servem como evidências e corroboram as ideias de PrIETO, Gomez e Sampaio ${ }^{24}$, e Modolo, Beltramini e Menezes $^{25}$, cujas revisóes (bibliográfica e sistemática, respectivamente) mostraram que há a preferência por estudos envolvendo equipes adultas e do sexo masculino. Apesar do crescente número de estudos com equipes do sexo feminino, ainda há escassez de estudos com categorias de base/formação.

Sendo assim, o objetivo deste estudo foi identificar os aspectos técnicos e táticos do jogo de handebol na categoria sub-14 feminina, a partir da opiniáo de treinadores, e suscitar uma reflexão acerca dos indicadores relevantes para a análise do jogo, considerando o contexto dinâmico das relaçóes entre os jogadores.

aprofundada e detalhada ${ }^{27}$.

Este estudo é parte de um projeto de pesquisa mais amplo, envolvendo treinadores de handebol de equipes femininas, que visa identificar aspectos relacionados aos conteúdos e ao ensino em cada faixa etária ou nível de jogo. Tais informaçôes poderão servir de base para subsidiar reflexóes acerca da implementação da análise de jogo na categoria sub-14. 
Pelo seu caráter qualitativo, foi desenvolvido um instrumento de entrevista semiestruturada ${ }^{26}$ que permitiu aos treinadores expressarem seus pensamentos em temáticas relacionadas com a compreensão de processos dinâmicos do jogo, em especial a identificação de parâmetros técnicos e técnico-táticos ofensivos e defensivos do jogo da categoria sub-14.

\section{Caracterização dos participantes}

Participaram deste estudo seis treinadores (S1 a S6) selecionados por conveniência. Não obstante, utilizouse como critério fundamental o grau de experiência destes com o handebol em diferentes categorias do processo de formação (o que proporciona uma visão de longo prazo e mais integrada). Constituíram-se como critérios específicos de inclusão: a) dirigir na época da pesquisa equipes femininas adultas de handebol do Estado de Sáo Paulo, Brasil; b) ter classificado sua equipe entre as três primeiras colocadas (na primeira ou segunda divisão) dos Jogos Abertos do Interior do Estado; c) ter atuado como treinador ou assistente em todas as categorias de formação. Embora um dos critérios de inclusão esteja relacionado ao fato de ser treinador de equipes adultas, e este estudo remeter-se especificamente à categoria sub-14, os seis treinadores possuíam experiências nas equipes sub-14 femininas (deste, quatro estavam em atividade na época da entrevista).

A média de idade dos entrevistados foi de 43 $( \pm 6,4)$ anos (mín=31, máx=49), com tempo médio de experiência profissional de $18( \pm 5,9)$ anos (mín=13, máx $=28)$ e graduados em Educação Física há uma média de $18( \pm 8,6)$ anos ( $m i ́ n=8$, máx=28). O tempo médio de experiência como treinador na categoria sub-14 era de $4( \pm 2,3)$ anos (mín=1, máx=8). Todos os treinadores assinaram um Termo de Consentimento Livre e Esclarecido previamente aprovado por um Comitê de Ética em Pesquisa institucional.

\section{Procedimentos e instrumento de entrevista}

Optou-se pela elaboração de um instrumento de entrevista semiestruturada que parte de questionamentos apoiados em hipóteses relevantes para pesquisa, havendo possibilidades para novas interrogativas, à medida que o entrevistado vai apresentando sua linha de pensamento ${ }^{28}$.

Por se tratar de um estudo que é parte de um projeto de pesquisa mais amplo sobre o processo de formação esportiva no handebol, a versão provisória da entrevista foi submetida a experimento piloto com um treinador de âmbito local. Diversos ajustes foram realizados por dois pesquisadores, de maneira consensual, a partir da análise das respostas do treinador. $\mathrm{O}$ instrumento da entrevista na versão modificada foi novamente testado com outro treinador, tendo sido considerado adequado, a partir da concordância dos pesquisadores e atendendo às prerrogativas iniciais do projeto de pesquisa.

$\mathrm{O}$ instrumento pautou-se nas seguintes perguntas norteadoras: a) "o que você acha que seus jogadores devam saber fazer individualmente nessa categoria para que o ataque seja eficaz?"; b) "o que você acha que seus jogadores devam saber fazer coletivamente nessa categoria para que o ataque seja eficaz?"; c) "o que você acha que seus jogadores devam saber fazer individualmente nessa categoria para que a defesa seja eficaz?"; d) "o que você acha que seus jogadores devam saber fazer coletivamente nessa categoria para que a defesa seja eficaz?". A prerrogativa foi identificar os conteúdos mais relevantes para o jogo na categoria sub14 para identificar os aspectos/conteúdos individuais e coletivos, ofensivos e defensivos. A descrição desses possibilitou apontar perspectivas de análise que contemplassem indicadores para a melhor compreensão do jogo nessa categoria.

Embora sejam admitidos diferentes contextos defensivos nessa categoria, marcadamente pelos sistemas individuais e zonais, a ideia de elaborar e aplicar questôes abertas sem especificar o sistema remete à identificação de parâmetros gerais. Assim sendo, a partir desses parâmetros (que são balizadores nessa categoria) outras interpretaçôes ou adaptaçôes podem ser realizadas mediante diferentes contextos.

As entrevistas foram realizadas por um pesquisador experiente da área da Pedagogia do Esporte com ampla vivência no handebol. Foi respeitado o calendário dos treinadores, priorizando situaçóes que não concorressem com suas atividades profissionais. Também foi dada preferência a locais nos quais a sua atenção pudesse ser dedicada exclusivamente ao pesquisador e com poucos ruídos que interferissem na qualidade de gravação dos áudios.

Os áudios foram transcritos na íntegra e as transcriçôes enviadas via e-mail aos treinadores como forma de validaçáo dos dados de natureza verbal. SARMENTO et al. ${ }^{9}$ afirmam que entrevistas com os treinadores podem ser usadas para encontrar diferentes aspectos, assim como para validar as variáveis a serem analisadas. 


\section{Análise dos discursos}

Para organizar, tabular e interpretar os depoimentos foi utilizado o método do Discurso do Sujeito Coletivo (DSC), no qual busca-se a expressão do pensamento de uma comunidade (ou coletividade) a partir da agregação de trechos contínuos ou descontínuos dos discursos, mantendo a coerência e a constituiçáo de cada uma das partes que o compóe ${ }^{29}$.

O DSC pauta-se na Teoria das Representaçôes Sociais, descrita por Serge Moscovici, com preocupação voltada ao processo de construção do conhecimento a partir da inter-relação entre sujeito e objeto, que é simultaneamente individual e coletivo ${ }^{30}$. O DSC pode revelar diferentes pensamentos sobre uma mesma temática e, embora constituam discursos diferentes, permitem a identificação e agrupamento de ideias semelhantes

\section{Resultados e discussão}

Após a análise dos discursos dos treinadores foi possível elaborar os DSC de modo a atender aos objetivos deste estudo, referentes à identificação dos aspectos técnicos e táticos do jogo de handebol na categoria sub-14 feminina.

Entendemos que a habilidade técnica deve ser executada em contexto de jogo, cuja intencionalidade deva ser predominante para a resoluçáo das situações com as quais os jogadores se deparam. Quando os treinadores se referiram a determinados elementos citados anteriormente, será adotada aqui a nomenclatura técnico-tática, ao invés da dicotomia técnica $\mathrm{x}$ tática.

A partir da inexorável relação entre os conteúdos específicos do processo de ensino e a análise de jogo ${ }^{10}$, as variáveis foram identificadas e contemporizadas com a literatura específica. Foi possível elaborar quatro DSC: DSC1 e DSC2 referentes às variáveis ofensivas; e DSC3 e DSC4 referentes às variáveis defensivas. O DSC1 (proveniente da IC-1: "Ênfase em diferentes fundamentos e meios técnicotáticos ofensivos", pautado na opiniáo de todos os treinadores) é assim apresentado:

DSC1: Já entra passe, recepçâao ${ }^{\$ 2, \$ 4,55, \$ 6}$, drible, trajetória,

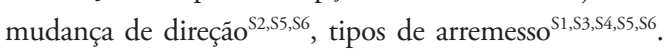
$\mathrm{O}$ drible tem que aprender, ainda mais quando vem a marcação individual ${ }^{\mathrm{S3}}$. Entram as fintas ${ }^{\mathrm{S3,55,56}}$ para evitar o contato dos defensores ${ }^{55}$; criar açóes como uma finta sem a partir de uma base indutiva, articulando diferentes argumentos de certa opinião, preservando o discurso da coletividade ${ }^{29}$.

Foram identificadas variáveis como as ideias centrais (IC) e as expressóes-chave (ECH), que são figuras metodológicas específicas para a elaboração do DSC e que, a partir de seus possíveis agrupamentos e reconstruçóes, expressam um discurso coletivo (DSC) elaborado na primeira pessoa, que retrata a síntese das expressões-chave com a mesma ideia central ${ }^{29,31}$. A identificação das IC e das ECH, bem como a elaboração dos respectivos DSC, foram realizados simultaneamente por dois pesquisadores com experiência na temática em questão.

Na seção "Resultados e Discussão" os DSC serão apresentados na íntegra, com a procedência da fala indicada de maneira sobrescrita.

\begin{abstract}
bola ou com bola ${ }^{\mathrm{S4}}$ e o desmarque nos espaços livres pra eles jogarem $^{\mathrm{S3}, \mathrm{S} 6}$. O mais difícil nessa categoria é o arremesso das pontas. Os pivôs já vão jogar de lado, de costas, pegar a bola em movimento, em parada. Coletivamente começam a surgir as açóes de circulação de ponta, a troca de sentido, de ritmo, quebras e o engajamento que é o mínimo necessário, no espaço interdefensivo $[\text { fixaçōes }]^{\mathrm{S}}$.
\end{abstract}

Há alusão no DSC1 aos fundamentos e meios técnico-táticos (arremesso, passe, recepção, drible, trajetória, mudança de direção, desmarque, finta e fixaçóes), no qual os treinadores se referiram majoritariamente às açóes individuais, além da menção a postos específicos, como o jogo dos pontas e pivô. Destaca-se a relação apontada no DSC1 entre os elementos do jogo e a orientaçáo espacial dos jogadores, manifestada tanto no posicionamento como nas direçôes/intenções das suas trajetórias.

De acordo com SAAVEDRA et al. ${ }^{19}$ uma das tendências para a análise estatística dos jogos envolve os indicadores de desempenho relacionados ao ataque. $\mathrm{O}$ mesmo estudo realça a importância de variáveis (ofensivas e defensivas) como arremessos, defesas do goleiro, faltas técnicas e roubadas de bola como sendo as mais frequentes (independente do status da equipe), e relacionadas à criação de situações ofensivas.

A entrada de segundo pivô pelos pontas e armadores também surge como importante elemento no DSC1. 
Quando ocorre a ocupação temporária do posto de pivô por um armador ou ponta, entendemos que há mudança de sistema ofensivo (como do 3:3 clássico para o 3:3 com dois pivôs, 2:4 ou 4:2), apontando a necessidade de considerar na análise tais mudanças. Cabe destacar, ainda, que tal discurso reforça a ideia de que uma possível análise da categoria aponta para um cenário complexo e diversificado. Esta situação talvez seja, em parte, explicada pela utilizaçáo tanto da marcação individual como de sistemas zonais diversificados ${ }^{\mathrm{b}}$, o que possivelmente levou os treinadores a valorizarem possíveis açôes individuais (pela obrigatoriedade da marcação individual), como apontado anteriormente.

Os treinadores também mencionaram a preocupaçáo com o comportamento e o posicionamento do pivô (assim como Santos et $a l .{ }^{32}$ ) por assumir uma posição diferente dos demais jogadores em relação ao gol e aos defensores, requisitando valências como força de membros superiores, resistência (principalmente de membros inferiores), força de no tronco, além de habilidades motoras básicas e específicas, que também pode variar de acordo com a faixa etária ${ }^{21}$. Sugerimos, portanto, que as relaçóes que se estabelecem entre o pivô e os restantes elementos, em especial perante defesas zonais, devem ser igualmente ser consideradas, elencadas a estruturas táticas de jogo como $2 \times 2$ e o $3 \times 3$, em diferentes regiôes da quadra. Desta maneira, ao identificar um possível bloqueio ofensivo ${ }^{c}$ realizado pelo pivô, por exemplo, seria interessante apontar as açôes realizadas pelos seus companheiros próximos (como a fixação ${ }^{\mathrm{d}}$ ), as respostas dos adversários e a continuidade do jogo ofensivo.

O mesmo ocorre nas situações $1 \times 1$, também mencionadas pelo DSC1, principalmente em alusão a meios como as fintas e os desmarquese . A apresentação dos indicadores para a análise de jogo deve considerar, portanto, a contextualização das açóes dos defensores e atacantes e as suas relaçóes, inclusive com a bola.

Já o DSC2 (proveniente da IC-2: "Saber jogar no $1 \times 1$ e dar continuidade para o jogo ofensivo", constituído a partir da opinião de S1, S3, S4, S5 e S6) é assim apresentado:

DSC2: Intensificamos o jogo $1 \mathrm{x} 1$ atacando nos espaços $^{51, S 3}$, sem mudança de direção e com mudança de direção ${ }^{\text {s1 }}$, trabalhando movimentos de ataque simples e açôes de engajamento ${ }^{S 6}$; tem que saber usar o 1 x1 na hora correta ${ }^{S 1, S 3}$, saber sair e se deslocar para ter noção do espaço ${ }^{\text {S3 }}$. Um segundo aspecto importante é dar continuidade ${ }^{S 1, S 4, S 5}$, porque muitas vezes elas param muito na falta ${ }^{\mathrm{S1}}$.

As situaçóes de $1 \mathrm{x} 1$ constituem a tônica central do DSC2, no qual os treinadores apontam uma conotação mais voltada ao jogo diante de defesas zonais, partindo da concepçáo de que o jogador deve compreender a sua relação com o adversário, com o espaço e com o tempo para ocupar os espaços. Nesse sentido sugerem as mudanças de direçáo e trajetória, com ou sem a bola (finta e desmarque) como elementos imprescindíveis para conseguir vantagens nessa situação.

Tais açôes estão presentes nos jogos desta faixa etária na visão dos treinadores entrevistados, principalmente devido aos diferentes tipos de marcação exigidos nos regulamentos das competiçóes. Por outro lado, os treinadores também manifestaram preocupação com a continuidade do jogo ofensivo, o que suscita a ideia das penetraçóes sucessivas e do jogo em grupos $(2 \times 2 \mathrm{e}$ $3 \times 3)$, principalmente diante da exigência do cenário defensivo zonal. Destaca-se, portanto, a estreita relaçáo com os princípios do jogo defensivo.

FERrari et al. ${ }^{22}$ evidenciam que dependendo dos padróes de jogo da equipe, as açôes com início, progressão e finalização, ou a perda de bola sem finalização, são mais ocorrentes do que ações a partir de uma situaçóes específicas do jogo (como cobranças de falta para a rápida finalização). Esse aspecto está diretamente relacionado à forma de utilização dos meios táticos coletivos para culminar em sequências ofensivas positivas para a equipe, mesmo que tais sequências sejam iniciadas por açóes individuais. Tais apontamentos dos autores reforçam a necessidade de analisar situaçóes de jogo a partir das interações entre os jogadores, partindo de indicadores específicos dessa categoria.

Quando a temática envolveu as variáveis defensivas, o DSC3 (proveniente da IC-3: "Ênfase em diferentes fundamentos e meios técnico-táticos defensivos", opiniâo compartilhada por todos os treinadores) foi assim elaborado:

DSC3: A gente pode começar a falar um pouco mais sobre profundidade, lateralidade, bloqueio $^{\mathrm{S2}}$, coberturas $^{\mathrm{S2}, \mathrm{S3}}$, entrar no conceito de flutuação, deslocamento ${ }^{\$ 2, \$ 4}$, trocas defensivas $^{\$ 4}$, antecipação $0^{\$ 1, \$ 2, \$ 3, S 5}$, interceptação, dissuasão $^{\mathrm{S1}}$, o gesto técnico defensivo, a postura defensiva ${ }^{\mathrm{S4}}$, o encaixe do jogador ${ }^{\$ 4, \$ 6}$ e continuidade desse encaixe ${ }^{\$ 4}$. Começa a aprimorar as questôes de marcar o atleta com bola, sem bola, que já bateu bola, que tá saltando ${ }^{\mathrm{S4}}$; fazer que elas entendam que é legal a defesa atacar o ataque, 
provocar o erro do adversário, ter uma leitura e antecipar ${ }^{\mathrm{S1}}$. Quando forma o 3:3 já começa a ter as noçôes de troca e de cobertura ${ }^{54}$. Tem que começar a trabalhar com pivôs ${ }^{52}$, diminuir o espaço do atacante ${ }^{\mathrm{S3}}$, roubar a bola ${ }^{\mathrm{S1}, \mathrm{S3}}$.

Os treinadores aludiram no DSC3 a fundamentos e meios técnico-táticos como dissuasão, flutuação, cobertura, marcação e bloqueio defensivof. A opinião dos treinadores vai ao encontro do trabalho de Menezes $^{39}$, de que alguns conceitos das táticas defensivas individuais e coletivas, tais como a busca pela recuperação da posse de bola a partir da pressão sobre os atacantes, o desenvolvimento da noção espacial do defensor e de uma estratégia de atuação diante dos seus oponentes devam ser observadas na fase defensiva.

Mais uma vez é externada a preocupação com as relaçóes entre os defensores e os atacantes, pois os meios táticos abordados no DSC3 estão relacionados a essas, seja a partir de comportamentos reativos ou antecipativos. Fica claro, ainda, assim como elucidado no DSC2, a íntima relação com os espaços da quadra, seja em função do jogador em posse da bola ou dos potenciais recebedores, a partir das diferentes configuraçôies que podem assumir na quadra.

Dentro do sistema defensivo proposto, cuja alusão no DSC3 se dá em relação aos sistemas zonais, a utilização de fundamentos e meios técnico-táticos possuem papel central, sendo abordados em um contexto que depende da interação com o adversário e atendendo aos princípios defensivos. Os tipos de sistemas defensivos possíveis na categoria sub-14 são variados, principalmente por estar sujeita aos regulamentos específicos das competiçóes, o que torna a sua análise ainda mais complexa. O DSC4 (pautado na IC-4: "Enfatizar diferentes sistemas defensivos", opinião compartilhada por S1, S2, S4, S5, S6) descreve tal variabilidade dos sistemas defensivos na categoria sub-14:

DSC4: Mantemos a marcação individual ${ }^{51,52, S 4, S 5}$ meia quadra ${ }^{\mathrm{S} 1}$ ou um quarto da quadra ${ }^{\mathrm{S}}{ }^{\mathrm{S}}$. Tem que saber trabalhar com defesa aberta ${ }^{\mathrm{S} 2}$ e em zona $^{\mathrm{S} 2, \mathrm{S6}}$. Mantemos a marcação valorizando as trocas, coberturas, ajudas ${ }^{S 1}$, com proximidade maior dos jogadores que estáo sem a bola ${ }^{55}$. Já consegue aprender os sistemas, entender as trocas, começar a fazer açóes defensivas combinadas ${ }^{54}$. Estamos lidando com sistemas mais abertos, como o $3: 2: 1^{S 2}$, o $3: 3^{S 1, S 2, \$ 4}$ e o $5: 1^{S 1}$, não marca 6:0 $0^{S 1, S 4}$. Dá para trabalhar um pouco mais no posicionado, ainda trabalha $o$ individual e vai abaixando, não deixaria de dar os avançados e os mistos, mas voltaria no 6:0 para trabalhar as dobras defensivas, as ajudas ${ }^{\mathrm{s} 6}$.

Dentro dos sistemas defensivos podem ocorrer tanto variações das ações táticas como do próprio sistema, nos quais há relação de cooperação entre os defensores (como dobras, trocas de marcação ${ }^{\mathrm{g}}$, coberturas, ajudas) que estáo marcando atacantes com e sem a posse da bola. Esse aspecto, apontado pelos treinadores, chama a atenção para que na análise de jogo da categoria sub-14 haja menção ao sistema defensivo indicando, ainda, contextos específicos (marcação individual x zonal). Entendemos que a forma de analisar o ataque diante da defesa individual deve ser diferente da zonal (como o 3:3 ou o 6:0), pois os diferentes conteúdos defensivos são utilizados de acordo com o comportamento ofensivo e pelo fato de serem defesas estruturalmente diferentes.

Destaca-se, ainda, que a análise do panorama defensivo deve contextualizar o sistema ofensivo e as açōes dos jogadores adversários (como indicado no DSC1 e no DSC2), sendo aspectos que tendem a deixar a análise de jogo mais complexa, mas descrevem de forma mais específica o cenário do jogo. Açóes defensivas como marcação, interceptação do passe (antecipação), trocas de marcação e possíveis deslocamentos (como a basculação $)^{\mathrm{h}}$ são fatores relevantes para a categoria sub-14 de acordo com os DSC apresentados e com diferentes autores ${ }^{5,40,41}$ e retratam o jogo dessa categoria.

Importa referir que tanto considerando a fase ofensiva do jogo como a defensiva, alguns meios técnico-táticos não foram mencionados nos DSC apresentados, porém são apresentados por diferentes autores como elementos importantes das equipes.

De maneira geral, os discursos dos treinadores revelaram importantes indicadores que podem constituir a análise nas fases ofensiva e defensiva do jogo na categoria sub-14. Pelo fato de considerar o jogo de handebol com soluções estruturais complexas ${ }^{15}$, salienta-se a necessidade de descrever os aspectos que possibilitem identificar o contexto no qual as açôes elencadas acontecem, considerando diferentes variáveis situacionais como o resultado da partida, desenvolvimento do placar ou localização da partida, além de variáveis de cargas internas (ex: fequência cardíaca) e externas (ex: saltos e cargas do jogador $)^{23}$. 
FIGURA 1 - Sumário dos indicadores ofensivos e defensivos sugeridos pelos treinadores e por diferentes autores.

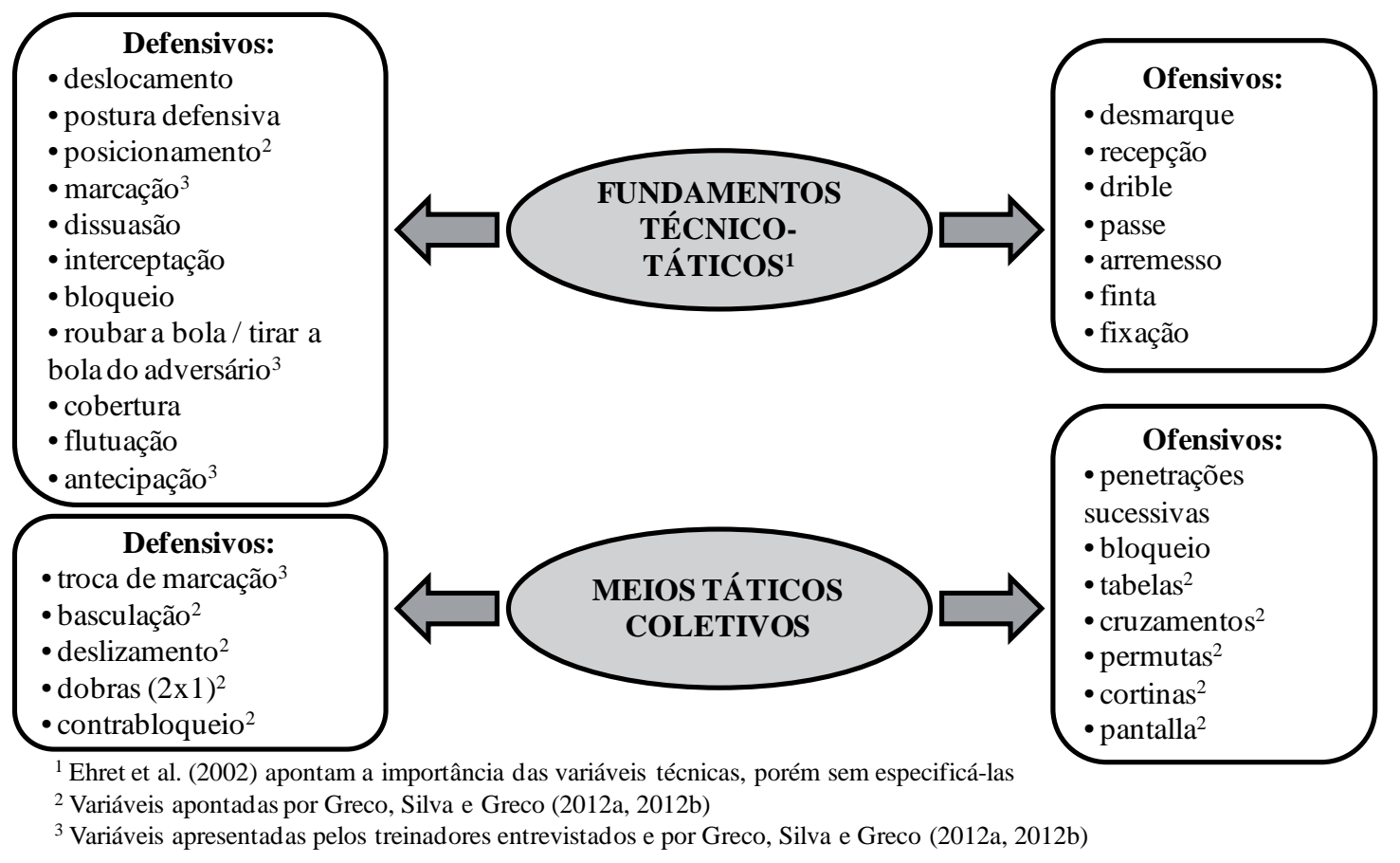

Os indicadores de jogo devem ser apresentados considerando a relação complexa com as questóes espaço-temporais, pelo fato de que alguns desses podem se manifestar diferentemente quando consideramos uma situação $2 \times 2$ na região central da quadra (como a interação armador central, pivô e seus respectivos marcadores) ou em uma lateral da quadra (como a interação entre armador, ponta e seus respectivos marcadores). A mesma ideia de interpretação se aplica às situaçóes $1 \times 1$ e 3x3, ao passo que informaçóes sobre a posição da bola são necessárias para a compreensão dos cenários mencionados. Considera-se, ainda, a necessidade de entender a estrutura do sistema ofensivo nas situações $2 \times 2$ e 3x3 (se há ou não pivô, se há apenas armadores, se há a presença de pontas), o que influencia as possíveis interaçóes entre os jogadores e, consequentemente, os meios táticos a serem utilizados.

Nessa direção, sugere-se que os indicadores apresentados pelos treinadores e pelos diferentes autores sejam apresentados de maneira contextualizada, conforme discutido anteriormente. A análise do jogo a partir desses indicadores pode proporcionar a identificação de comportamentos individuais e coletivos em diferentes situaçóes, para que seja operacionalizada no sentido de fornecer informaçóes considerando as relaçóes espaço-temporais das açóes dos jogadores e a posição da bola.

Na FIGURA 2 está apresentado um fluxogramasíntese sugerido para a análise nessa categoria, partindo de informaçóes norteadoras em direção à compreensão de situaçóes menores do jogo. É importante destacar que o rol de indicadores ofensivos e defensivos apresentado na FIGURA 1 pode servir como norteador para o processo de identificação de comportamentos técnico-táticos.

Em situaçóes como 1x1, 2x2 ou 3x3 (sendo as duas últimas pouco abordadas nos DSC) pode-se observar os comportamentos individuais e grupais dos jogadores, que utilizam diferentes informações provenientes dos adversários e dos companheiros para tomar suas decisóes. A perspectiva apresentada na FIgura 2 contempla o comportamento técnico e técnico-tático dos jogadores nas referidas situaçóes na categoria sub14, possibilitando a identificação de açôes em pequenos grupos e com curta duração ${ }^{40-42}$.

A ideia passa a ser de, a partir da identificação do contexto espaço-temporal, considerar as relaçóes numéricas setoriais (aplicáveis tanto para sistemas defensivos zonais como individuais), bem como as açóes ofensivas e defensivas naquele setor, mapeando 
os comportamentos dos jogadores na tentativa de compreender tais situaçôes. Sugere-se, assim, que os indicadores apresentados na FIGURA 1 sejam balizadores para os processos de elaboração do instrumento específico, observação do jogo e posterior análise.

Sousa et al. ${ }^{43}$ analisaram as relaçóes $2 \times 2 \mathrm{em}$ 16 partidas do Campeonato Europeu Masculino de Handebol de 2012 com o intuito de estudar e caracterizar os padróes ofensivos de conduta e as açôes táticas diante de diferentes sistemas defensivos. De maneira geral, as equipes apresentaram diferentes padróes e ações preferidas, o que variou de acordo com os sistemas defensivos (em especial o 6:0 e o $3: 2: 1$ ), principalmente por estes serem concebidos com diferentes relaçóes de cooperação e de açóes táticas. Nesse sentido, espera-se que na análise da categoria sub-14, devido às exigências regulamentares das competiçóes, os jogadores possam optar diferentemente por açóes diante de defesas individuais e zonais, por apresentarem diferentes percepções sobre a ocupação espacial. Ao mesmo tempo, espera-se que o rol de indicadores apontado na FIGURA 1 sirva como subsidio por fornecer importantes informaçóes aos treinadores que, a partir dos conceitos abordados nos seus treinamentos, poderão enfatizar determinados indicadores ofensivos e/ou defensivos.

FIGURA 2 - Fluxograma proposto para construção do modelo de análise de situações dejogo na categoria sub-14.

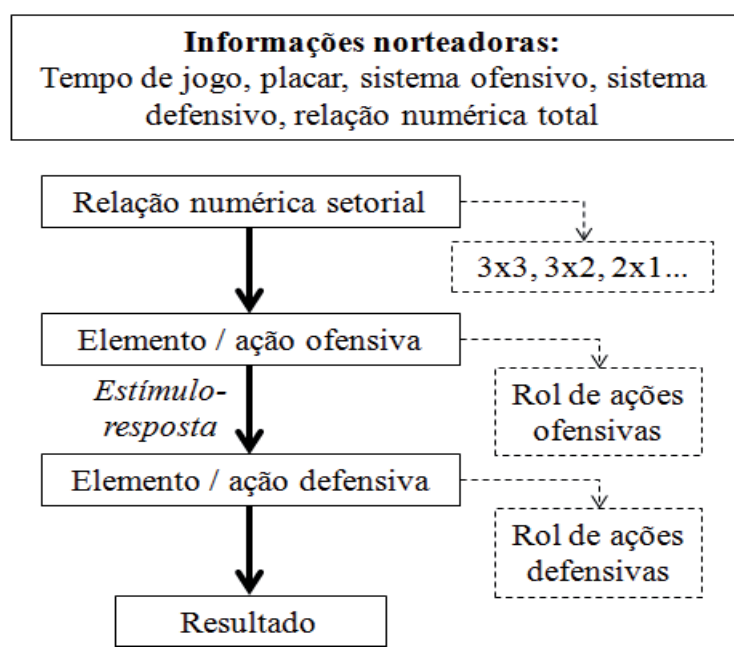

Diferentemente de outras propostas para a análise de parâmetros quantitativos do jogo, que não apresentam de maneira significativa o contexto do jogo e as relaçóes entre os jogadores, houve a tentativa neste estudo de identificar indicadores para a análise da categoria sub-14 a partir da opinião dos treinadores, que possam subsidiar o desenvolvimento de um modelo de análise do jogo. Trata-se não apenas de quantificar a frequência dos fundamentos e meios técnico-táticos, mas de buscar as razóes pelas quais os jogadores os manifestaram naqueles contextos. Sugere-se, para isso, que o instrumento utilizado pelos treinadores para a analisar suas equipes seja capaz de revelar um panorama/cenário das açóes ofensivas e defensivas não isoladamente, mas destacando suas interaçóes.

O mapeamento do comportamento dos atacantes e defensores em situações 1x1, 2x2 e 3x3 e em contexto de marcação individual e zonal pode trazer indicativos sobre a estruturação espacial e a coordenação das açóes entre os jogadores. Parte-se do pressuposto de uma análise centrada no próprio jogo a partir de relaçóes numéricas menores, nas quais é possível identificar as açóes dos atacantes e as possíveis respostas dos defensores. A análise nesse panorama de menores relaçóes numéricas deve atentar-se para as mudanças de posição na largura e na profundidade da quadra ${ }^{40,41}$ que fundamentam o desenvolvimento de diferentes fundamentos e meios técnico-táticos ofensivos e defensivos. 
As situaçóes de jogo apresentam conotaçóes diferentes em função da regiāo da quadra na qual ocorrem, por isso a preocupação externada neste estudo com a necessidade de considerar as questóes espaço-temporais. Um exemplo dessa afirmação se manifesta em uma situação $2 \times 2$ diante da marcação individual, que pode ocorrer próxima ou distante do gol, na região central ou lateral da quadra e as possíveis interaçóes entre essas (próxima no centro, próxima na lateral, distante no centro e distante na lateral). Para a mesma situação $(2 \times 2)$, mas considerando a marcação zonal, as interações entre os jogadores podem ser diferentes, pois dependerão das possibilidades que o sistema defensivo oferecerá para o jogo em profundidade, requisitando relaçóes de cooperaçáo diferentes das apresentadas diante da marcação individual.

Considerar as tarefas realizadas pelos jogadores e pela equipe é fundamental para os modelos de treino e de jogo, de maneira a buscar melhor compreensão do ambiente do jogo e almejar situaçóes de treino mais próximas à realidade do jogo. A análise de jogo é considerada primordial no treino e na competição, cujos parâmetros auxiliam no planejamento e no controle dos treinamentos ${ }^{8,19,20,23}$ e possibilitam a transferência das competências treinadas às competiçôes ${ }^{11}$. Por esse motivo, este estudo pautouse no destaque aos contextos promovidos pelas interaçóes entre atacantes e defensores em situaçóes com relaçóes numéricas de $1 \times 1,2 \times 2$ e $3 \times 3$ nas quais, a partir da identificaçáo dos indicadores ora apresentados, permitem elaborar exercícios para os treinamentos que atendam especificamente às demandas.

Entendemos, portanto, que ouvir a opinião dos treinadores constitui-se como um aspecto relevante para o balizamento da análise de jogo, por partir de parâmetros que permitem, inclusive, abrir novos horizontes para a compreensão das diferentes formas de manifestação do handebol, neste caso na categoria sub14. Cabe destacar que a partir desse mapeamento será possível elaborar modelos de análise que não pautem-se apenas no número de ocorrências de tais fundamentos e meios técnico-táticos, mas uma compreensão da manifestação desses nas diferentes relaçôes numéricas do jogo $(1 \times 1,2 \times 2 \ldots)$ considerando-se as questóes espaço-temporais.

Observamos que a análise de jogo do handebol tem sido pautada majoritariamente na análise sequencial, na tentativa de buscar parâmetros quantitativos de como são realizadas, individualmente, as açôes dos jogadores durante o jogo. Geralmente são compostas por quatro parâmetros: "qual ação foi realizada?”, "quem realizou a ação?", "quando a ação foi realizada" e "onde se realizou a ação?"11.

Apesar de ser uma técnica de fácil aplicação, sobretudo com os avanços dos recursos computacionais, pouco consegue explicar sobre a dinâmica do jogo, uma vez que permite apenas seguir o curso da bola e das açóes que lhe estâo inerentes, e não possibilita a realizaçáo de uma análise dos vários comportamentos em paralelo. Questiona-se, ainda, a relevância desse tipo de análise para a compreensão do contexto no qual as açóes são realizadas, emergindo a necessidade de relacioná-las às situaçóes do jogo.

A representação de ação por ação de modo sequencial não possibilita compreender comportamentos simultâneos e as relaçôes possíveis entre $\mathrm{o}$ jogador em posse da bola e seus companheiros, tal como identificar seus deslocamentos na tentativa de, por exemplo, criar linha de passe ou mesmo de chamar a atenção dos adversários para outras regióes da quadra. Considerando as dificuldades em analisar e avaliar o handebol, que residem principalmente no fato de não apenas quantificar açóes/comportamentos, mas de qualificá-los ${ }^{44}$, torna-se necessário considerar a influência das interaçóes entre os jogadores para que a análise represente, de fato, o cenário do jogo.

Conclui-se que a análise de indicadores técnicotáticos específicos da categoria sub-14, manifestados em diferentes constrangimentos de jogo (como a marcação individual e zonal) pode apresentar contribuiçóes aos treinadores no planejamento e na intervenção das sessóes de treinamento. Tal perspectiva se dá a partir de indicadores que estejam fortemente relacionados com a construção das soluções de jogo a partir da inter-relação entre atacantes, oponentes e bola, que é simultaneamente individual, cooperativa e de confronto.

Assim, a análise de jogo deve considerar as relaçoóes de confronto (como 1x1, 2x2 e 3x3) do jogo de handebol na categoria sub-14, e que possuam íntima relação com o aprendizado do jogo. Entretanto, o estudo destas relaçóes não pode ser feito de forma isolada das variáveis espaço-tempo, onde a posição relativa à baliza, que se a ataca ou defende, é decisiva.

As informaçóes provenientes dos indicadores identificados neste estudo dão corpo a um conjunto de parâmetros a serem considerados na construção de instrumentos de análise do jogo para a categoria em análise. Tais parâmetros constituem- 
se em indicadores técnicos e táticos ofensivos e defensivos, ficando evidente a necessidade de se considerarem constrangimentos situacionais em que se manifestaram, incluído a sua dependência da posição da bola e da própria dinâmica do jogo.

Cabe destacar que uma possível limitaçáo deste estudo reside no fato de basear-se apenas nos discursos de treinadores de equipes femininas e que, ao estender a treinadores de equipes masculinas, outros indicadores poderiam ser identificados por uma possível influência de outros fatores relacionados às questóes maturacionais, antropométricas e de desenvolvimento das capacidades físicas (o que mostraria ênfases diferentes nos treinamentos de equipes masculinas e femininas). Como perspectivas futuras aponta-se o estudo da opinião dos treinadores que estão atualmente nessas categorias, assim como o desenvolvimento de um modelo de análise de jogo a partir dos indicadores identificados neste estudo.

\section{Apoio financeiro}

Fundação de Amparo à Pesquisa do Estado de São Paulo (FAPESP, processo 2013/05854-8), Conselho Nacional de Desenvolvimento Científico e Tecnológico (processo 163671/2014-1), Coordenação de Aperfeiçoamento de Pessoal de Nível Superior - Brasil (CAPES) - Código de Financiamento 001.

\section{Notas}

a. Há diferentes classificaçóes para os elementos que constituem o jogo de handebol, com exceção dos sistemas de jogo. KNiJNiK ${ }^{3}$ utiliza as denominações de meios táticos para o ataque organizado, técnicas de ataque. Já para Menezes ${ }^{4}$ há os fundamentos (técnica - ofensiva e defensiva), os meios técnico-táticos ofensivos e defensivos (ambos dividindo-se em individuais e coletivos). Tal diferença apresentada nas classificaçóes e nos respectivos elementos pertencentes a cada um mostra a dificuldade em agrupar elementos no handebol, carecendo de estudos mais aprofundados nessa temática.

b. Federação Paulista de Handebol (FPH): 2x25 minutos (quatro períodos de 12’30”): $1^{\circ}$ período: defesa individual em meia quadra, pelo menos, $2^{\circ}$ período: defesa 5:1, $3^{\circ}$ período: defesa 3:3, 4º período: livre com exceção do 6:0 e defesas mistas (http://www.fphand.com.br/index.php?option=com_content \&view=article\&id=3321:fphb-divulga-as-regras-adaptadas-para-categoria-infantil-leia\&catid=24:infantil\&Item id=310). Liga de Handebol do Estado de São Paulo (LHESP): 2x20 minutos (com os 10 iniciais de cada tempo com marcação individual e os 10 finais com qualquer sistema, exceto mistos) (http://www. lhesp.com.br/anexos/Regulamento_2015.pdf). Liga Paulistana de Handebol (LPHb): 2x20 minutos, sem dispor sobre a marcação (http://www.lphb.com.br/boletins/regulamento_2016.pdf). Confederação Brasileira de Handebol (CBHb): 2x20 minutos (4 períodos de 10 minutos), sendo: $1^{\circ}$ período: marcação individual $1 / 2$ quadra, $2^{\circ}$ e $3^{\circ}$ períodos: defesa em duas linhas, sem marcação individual, $4^{\circ}$ período e prorrogação: qualquer sistema defensivo (http://www.brasilhandebol.com.br / Admin/Anexos/001175_REGULAMENTO\%20CB\%20INFANTIL\%20DE\%20CLUBES\%202014.pdf).

c. Bloqueio ofensivo pode ser entendido como uma açáo realizada por um atacante com ou sem a posse da bola que ocupa um determinado espaço na quadra e interrompe o deslocamento de um defensor ${ }^{4,33}$.

d. Molina ${ }^{34}$ aponta que a fixação se refere à ação para chamar a atenção de um defensor, fixando o marcador em uma determinada posição vantajosa para o atacante, que podem ter por finalidade a obtenção de superioridade numérica para a progressão ou infiltração do ataque ${ }^{33,35}$.

e. A finta é caracterizada como uma ação executada por um jogador com a posse da bola que, ao final de sua progressão, muda a direção do seu deslocamento para vencer a oposição de defensor ${ }^{4}$. Já o desmarque é caracterizado por sucessivas mudanças de direção das trajetórias para livrar-se de um marcador direto que esteja muito próximo ${ }^{4}$.

f. Os meios táticos defensivos aqui citados são assim definidos: a) flutuação - ação de aproximação-afastamento do defensor em relação ao seu oponente $\mathrm{e}^{33}$ na tentativa de impedir que o atacante em posse da bola aproxime-se de setores onde tenha melhores possibilidades de arremesso; b) dissuasão - tem características funcionais semelhantes à flutuação, mas é realizada pelo defensor que marca um atacante sem a bola (potencial recebedor) com o objetivo de gerar dúvidas ao passador ${ }^{4}$, perturbar, dificultar $\mathrm{e}$ atrasar a circulaçáo da bola, impedindo certas trajetórias do atacante ${ }^{36}$; c) cobertura - deslocamentos defensivos que objetivam a criação de densidade na zona da bola para fechar os espaços dos atacantes e dar respaldo ao oponente direto do possuidor da bola ${ }^{37}$; d) marcação - atitude do defensor em relação ao seu marcador direto ou indireto na tentativa de 
obter êxito4, podendo ser executada à distância ou em proximidade ${ }^{38}$; e) bloqueio defensivo - tentativa dos defensores de impedir que a bola chegue ao gol após um arremesso pela interceptação direta da sua trajetória ${ }^{37}$.

g. Os meios táticos aqui apresentados são assim definidos: a) dobra - caracterizada pela atuação de dois defensores para conter a ação de um atacante em posse da bola que superou um companheiro de um posto específico vizinho ${ }^{4,33}$; b) troca de marcação - dois defensores mantêm seus postos específicos mediante uma troca de posição dos atacantes (gerando uma troca dos marcadores diretos) para não desestruturar espacialmente a organização defensiva ${ }^{33}$.

h. A basculação se caracteriza como um movimento conjunto dos defensores (deslocamentos laterais coletivos) em função da direção de circulação de bola ${ }^{4,33,37}$.

\begin{abstract}
Performance indicators for a model of match analysis of handball in U-14 teams from coaches' speeches

Different methods have been used to analyze the handball game based on indicators of adult teams, which are difficult to generalize to other categories (such as under-14). The aim of this study was to map the variables relevant to match analysis of $\mathrm{U}-14$ handball teams, based on coaches interviews $(n=6)$. Semi structured interviews were conducted with coaches from the State of São Paulo, analyzed using the Collective Subject Discourse method. Eighteen performance indicators related to technical-tactical principles ( 11 defensive and 7 offensive) and 12 related to collective tactical elements (five defensive and seven offensive) were identified. These performance indicators refer to possible relationships between players in game situations, which need to be analyzed in the context in which they occur. It is suggested that the proposals for match analysis in U-14 teams consider the relationships between teammates and opponents, based on the indicators listed by coaches and by different authors, especially in 1vs.1, 2vs.2 and 3vs.3 situations. These analyzes should allow the identification of aspects related to the game context that can be emphasized in the training sessions, starting from the previously mentioned numerical relations and the position of the ball, and not only describing the number of occurrences of the indicators.
\end{abstract}

KEYwoRDs: Team sports; Match analysis; Team handball; Performance indicators; Coaches.

\title{
Referências
}

1. Garganta J. Para uma teoria dos jogos desportivos colectivos. In: Graça A, Oliveira J, editores. O ensino dos jogos desportivos. 3 ed. Porto: Universidade do Porto/Centro de Estudos dos Jogos Desportivos; 1998. p. 11-26.

2. Gréhaigne J-F, Godbout P. Tactical knowledge in team sports from a constructivist and cognitivist perspective. Quest. 1995;47:490-505.

3. Knijnik J. Handebol. 1 ed. São Paulo: Odysseus; 2009.

4. Menezes RP. Modelo de análise técnico-tática do jogo de handebol: necessidades perspectivas e implicações de um modelo de interpretação das situaçóes de jogo em tempo real. Campinas: Universidade Estadual de Campinas; 2011.

5. Greco PJ, Silva SA, Greco FL. Identificação, caracterização e classificação do jogo de handebol. In: Greco PJ, Fernández Romero JJ, editores. Manual de handebol: da iniciação ao alto nível. São Paulo: Phorte; 2012. p. 33-54.

6. Prieto J, Gómez M-Á, Sampaio J. From a static to a dynamic perspective in handball match analysis: a systematic review. Open Sports Sci J. 2015;8:25-34.

7. Prudente J, Garganta J, Anguera MT. Desenho e validação de um sistema de observação no andebol. Rev Port Ciênc Desporto. 2004;4(3):49-65.

8. Menezes RP, Reis HHBd. Análise do jogo de handebol como ferramenta para sua compreensão técnico-tática. Motriz. 2010;16(2):458-67.

9. Sarmento H, Anguera MT, Pereira A, Marques A, Campaniço J, Leitão J. Patterns of play in the counterattack of elite football teams - a mixed method approach. Int J Perform Anal Sport. 2014;14(2):411-27. 
10. Wright C, Carling C, Collins D. The wider context of performance analysis and it application in the football coaching process. Intern J Perform Anal Sport. 2014;14:709-33.

11. Garganta J. A análise da performance nos jogos desportivos: revisão acerca da análise do jogo. Rev Port Ciênc Desporto. 2001;1(1):57-64.

12. Srhoj V, Rogulj N, Katic R. Influence of the attack end conduction on match result in handball. Collegium Antropologicum. 2001;25(2):611-7.

13. Meletakos P, Vagenas G, Bayios I. A multivariate assessment of offensive performance indicators in men's handball: trends and differences in the World Champinships. Intern J Perform Anal Sport. 2011;11:285-95.

14. Lennartsson J, Lidström N, Lindberg C. Game intelligence in team sports. PLoS ONE. 2015;10(5):1-28.

15. Pfeiffer M, Perl J. Analysis of tactical structures in team handball by means of artificial neural networks. Intern J Computer Sci Sport. 2006;5(1).

16. Prudente J. Andebol. In: Garganta J, Prudente J, Anguera T, editores. Avaliação da performance em jogos desportivos coletivos. Porto: Centro de Investigação, Formação, Inovação e Intervenção no Desporto (CIFI2D); 2013. p. 9-77.

17. Queirós P, Lacerda T. A importância da entrevista na investigaçáo qualitativa. In: Mesquita I, Graça A, editorqs. Investigação qualitativa em desporto. 2. Porto: Centro de Investigação, Formação, Inovação e Intervenção em Desporto; 2013. p. 175-206.

18. Gomes F, Volossovitch A, Ferreira A. Efeitos do pedido de timeout de equipa na performance colectiva no andebol em função do contexto do jogo. Rev Bras Educ Fís Esporte. 2018;31(2):413-21.

19. Saavedra J, Porgeirsson S, Chang M, Kristjánsdóttir H, García-Hermoso A. Discriminatory power of women’s handball game-related statistics at the Olympic Games (2204-2016). J Human Kinetics. 2018;62(1):221-9.

20. Dello Iacono A, Martone D, Zagatto A, Meckel Y, Sindiani M, Milic M, et al. Effect of contact and no-contact small-sided games on elite handball players. J Sports Sci. 2018;36(1):14-22.

21. Bojić-Ćaćić L, Vuleta D, Milanović D, Barišić V, Jerak T, editors. Age differences among the Croatian female young pivots in the indicators of basic and handball-specific physical fitness. 14th International Scientific Conference of Sport Kinetics; 2018; Porec, Croatia.

22. Ferrari W, Vaz V, Sousa T, Couceiro M, Dias G. Comparative analysis of the performance of the winning teams of the Handball World Championship: Senior and Junior levels. Intern J Sports Sci. 2018;8(2):43-9.

23. Triguero D, Reina M, Baquero B, García-Rubio J, Ibáñez S. Carga competitiva en jugadores de balonmano de formación en función del resultado final. E-Balonmano.com: Rev Cienc Deporte. 2018;14(2):99-108.

24. Prieto J, Gómez MA, Sampaio J. A bibliometric review of the scientific production in handball. Cuad Psicoll Deporte. 2015;15(3):145-54.

25. Modolo F, Beltramini L, Menezes R. Revisão sistemática sobre o processo de ensino e de análise do goleiro de handebol. Cuad Psicol Deporte. 2018;18(3):232-49.

26. Marconi M, Lakatos E. Metodologia científica. 6 ed. São Paulo: Atlas; 2011.

27. Richardson RJ. Pesquisa social: métodos e técnicas. 3 ed. São Paulo: Atlas; 1999.

28. Triviños A. Introdução à pesquisa em ciências sociais: a pesquisa qualitativa em educação. 1 ed. São Paulo: Atlas; 1987.

29. Lefèvre F, Lefèvre AMC. Pesquisa de representação social: um enfoque qualiquantitativo. 2 ed. Brasília: Liber Livro Editora; 2012.

30. Crusoé NMdC. A Teoria das Representações Sociais em Moscovici e sua importância para a pesquisa em educação. Aprender: Cad Fil Psicol Educ. 2004;II(2):105-14.

31. Lefevre F, Lefevre AMC. Discurso do sujeito coletivo: um novo enfoque em pesquisa qualitativa. 1 ed. Caxias do Sul: EDUCS; 2003.

32. Santos F, Fernandez J, Oliveira M, Leitão C, Anguera M, Campaniço J. The pivot player in handball and patterns detection - instrument. Motricidade. 2009;5(3):29-36.

33. Fernández Romero JJ, Casais Martínez L, Vila Suárez H, Cancela Carral JM. Balonmán: manual básico. Santiago: Edicións Lea; 1999.

34. Feu Molina S. Organización didáctica del proceso de enseñanza-Aprendizaje para la construcción del juego ofensivo en balonmano. E-Balonmano. 2006;2(4):53-66.

35. Menezes RP. Das situacóes do jogo ao ensino das fixacóes no handebol. Motriz. 2011;17(1):39-47.

36. Bayer C. Técnica del balonmano: la formación del jugador. Barcelona: Editorial Hispano-Europea; 1987.

37. Antón García JL. Balonmano: táctica grupal defensiva. Concepto, estructura y metodología. Granada: Grupo Editorial Universitario; 2002. 
38. Oliver Coronado JF, Sosa González PI. La actividad física y deportiva extraescolar en los centros educativos: Balonmano. Barcelona: Ministerio de Educación y Cultura/Consejo Superior de Deportes; 1996.

39. Menezes RP. O ensino dos sistemas defensivos do handebol: consideraçóes metodológicas acerca da categoria cadete. Pensar Prát. 2010;13(1):1-16.

40. Ehret A, Späte D, Schubert R, Roth K. Manual de handebol: treinamento de base para crianças e adolescentes. São Paulo: Phorte Editora; 2002.

41. Greco PJ, Silva SA, Greco FL. O sistema de formação e treinamento esportivo no handebol brasileiro (SFTE-HB). In: Greco PJ, Fernández Romero JJ, editors. Manual de handebol: da iniciação ao alto nível. São Paulo: Phorte; 2012. p. 235-50.

42. Santos LR. Tendências evolutivas do jogo de andebol: estudo centrado na análise da performance táctica de equipes finalistas em campeonatos do mundo e jogos olímpicos. Porto: Universidade do Porto; 2004.

43. Sousa DJ, Prudente JN, Sequeira P, López-López JA, Hernández-Mendo A. Análisis de las situaciones de juego 2vs 2 en el campeonato europeo masculino de balonmano 2012: aplicación de la técnica de coordenadas polares. Cuad Psicol Deporte. 2015;15(1):181-93.

44. Garganta J. Trends of tactical performance analysis in team sports: bridging the gap between research, training and competition. Rev Port Ciênc Desporto. 2009;9(1):81-9.

\begin{tabular}{r|l} 
ENDEREÇO & \\
Rafael Pombo Menezes & Submetido: 20/06/2018 \\
heir, 3900 - Monte Alegre & Revisado: 11/ 12/2018 \\
beiroto - SP - Brasil & Aceito: 21/04/2019
\end{tabular}
Av. Bandeirantes, 3900 - Monte Alegre 14040-907 - Ribeirão Preto - SP - Brasil

E-mail: rafaelpombo@usp.br rpmenezes14@gmail.com

Revisado: 11/ 12/ 2018 